\title{
Computational insights on carbonate-silicate-metal melt behavior in the lower mantle
}

\author{
A.H. DAvis ${ }^{1 *}$, N.V. Solomatova ${ }^{2}$, R. CARACAS ${ }^{2}$, \\ AND A.J. CAMPBELL ${ }^{1}$ \\ ${ }^{1}$ University of Chicago, Chicago, IL 60637, USA \\ (*correspondence: ahdavis@uchicago.edu) \\ ${ }^{2}$ CNRS Lyon, BP 61335, 69609, Lyon, France
}

Carbonate melt is an important carbon-bearing phase in the mantle. While its role in the upper mantle has been well studied [1, 2], its importance in the lower mantle is less understood. The behavior of carbonate melt in the lower mantle is complicated by pressure, temperature, and $\mathrm{fO}_{2}$ conditions [3], as well as reactions with common lower mantle phases such as $\mathrm{MgSiO}_{3}$ and metallic iron [4].

We performed $a b$ initio molecular dynamics simulations on an $\mathrm{Mg}_{24} \mathrm{Si}_{12} \mathrm{C}_{12} \mathrm{O}_{72} \mathrm{Fe}_{13}$ melt composition (i.e. $12 \mathrm{MgCO}_{3}+$ $12 \mathrm{MgSiO}_{3}+13 \mathrm{Fe}$ ) at conditions up to $135 \mathrm{GPa}$ and $4000 \mathrm{~K}$ to understand speciation and coordination of carbonate melts in the lower mantle and at the core-mantle boundary. We find a rich diversity of species in our carbonate-silicate-metal melt, with our system displaying various carbon bonding environments. We determine that as the overall coordination of carbon increases with pressure, the abundance of C-Cbonds decreases with pressure and is compensated by an increase in $\mathrm{C}-\mathrm{Fe}$ and $\mathrm{C}-\mathrm{Si}$ bonding. We evaluate the implications of these chemical and structural changes for the storage and cycling of carbon in Earth's mantle.

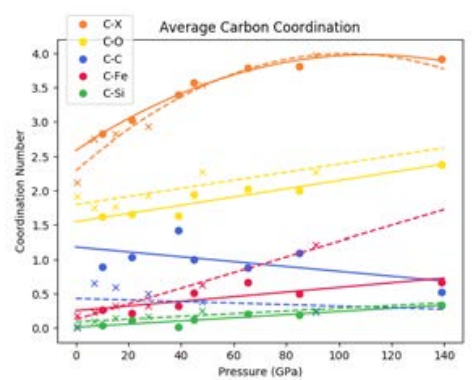

Figure 1: The average coordination of carbon bonded to all elements (orange), oxygen (yellow), carbon (blue), iron (red), and silicon (green). This study (solid lines) is compared to Solomatova et al. [5] (dashed lines).

[1] Braunger et al. (2020) EPSL 533, 116041. [2] Stagno et al. (2018) Chemical Geology 501, 19-25. [3] Rohrbach \& Schmidt (2011) Nature 472, 209-212. [4] Dorfman et al. (2018) EPSL 489, 84-91. [5] Solomatova et al. (2019) Nature Communications 10. 